\title{
Can Literature Improve English Proficiency: The Students Perspective
}

\author{
Gopala Krishnan Sekharan Nair ${ }^{1}$, Roszainora Setia ${ }^{1}$, Siti Norliana Ghazali ${ }^{1}$, Elangkeeran Sabapathy ${ }^{1}$, Razita \\ Mohamad $^{1}$, Myshithah Mohamad Ali ${ }^{2}$, Mohan K. Muniandy ${ }^{3}$, Ramachandran Theethappan ${ }^{3}$, Wan Aida Wan \\ Hassan $^{4} \&$ Nor Syamimi Iliani Che Hassan ${ }^{4}$ \\ ${ }^{1}$ Academy of Language Studies, Universiti Teknologi MARA (UiTM), Dungun, Malaysia \\ ${ }^{2}$ Bukit Besi Primary School, Dungun, Terengganu, Malaysia \\ ${ }^{3}$ Academy of Language Studies, Universiti Teknologi MARA (UiTM), Kuala Pilah, Negeri Sembilan, Malaysia \\ ${ }^{4}$ Academy of Language Studies, Universiti Teknologi MARA (UiTM), Machang, Kelantan, Malaysia \\ Correspondence: Gopala Krishnan Sekharan Nair, Academy of Language Studies, Universiti Teknologi MARA \\ (UiTM), Dungun Campus, 23000 Dungun, Malaysia. Tel: 60-9-8400-8225/60-12-900-2602. E-mail: \\ gopa1792@tganu.uitm.edu.my
}

Received: March 14, 2012 Accepted: July 5, 2012 Online Published: September 20, 2012

doi:10.5539/ass.v8n12p21 URL: http://dx.doi.org/10.5539/ass.v8n12p21

\begin{abstract}
Promoting the interest of learning English Language through the teaching of literature is considered to improve the proficiency of the students in the target language too. Therefore, this study aims to investigate whether the teaching of literature promotes students' proficiency in the target language. Thus this study has taken into account the students' feedback on the subject, teaching methodologies employed by teachers and the literary texts used in the school. The survey was conducted at SMK Bukit Besi to elicit information on the students' perception and interest towards literature as part of their English Syllabus. A total of 50 respondents were selected and given a set of questionnaire to provide the data. Based on the findings, it was found out that learning literature has indeed assisted them to improve their grasp of the target language. It was also found that students perceive learning literature as important and integral in the holistic development of language of the students. The study also determined that the approach and styles of the teacher, choice of literary texts and students' interest determine a successful programme. Future researchers should widen their scope of research by a more varied and wider sampling.
\end{abstract}

Keywords: extensive reading, teaching literature, perceptions, proficiency, syllabus

\section{Introduction}

The status and position of English in our country (Malaysia) has evolved and undergone changes since the colonial period. As a result of globalization and rapid advances in information and communication technology (ICT), there has been a change in priorities towards English. Although English remains as the second language, it is becoming more significant as it is the language used in Science and technology. The Malaysian education system is responding towards this as English is an important vehicle to opening doors of knowledge in science and technology, which is the pre-requisite towards becoming a developed nation by the year 2020 .

Currently, the standard of English in our country is deteriorating. Having realized this situation, several measures are being taken by the government to counteract the decline of the language. One of the measures is the introduction of English Literature into the English Language syllabus in schools. Apart from this, other measures which have been introduced earlier such as reading programs and class reader are being reviewed due to discouraging responses from the students as well as teachers.

The Ministry of Educations has finally decided to make literature a part of the PMR and SPM examination. This will make the subject more important and hopefully it would be treated more seriously by both teachers and students. The students are expected to cultivate their reading habits through this move. It is hoped that literature would be a great tool and resource for language teaching as it has authentic and interesting texts chosen which would benefit the process of foreign language learning.

The texts would encourage students to read and thus promote language acquisition and expand students' language awareness. Conventionally the students learn purely grammar and technicalities of the language but 
with the introduction of literature in the curriculum, literature lessons should be enjoyable and meaningful.

Therefore, this study proposes to investigate the students' attitude and perception towards literature in improving their English proficiency. It also aims to seek answers as to whether literature assists students' enrichment of vocabulary and whether the students' reading and writing skills improve through English Literature. The scope of study also involves in finding out their opinions about Literature texts and the styles of teaching by teachers teaching English Literature in the classrooms.

The English Language Syllabus for Schools in Malaysia: English is supposed to be taught as a second language in schools but in reality it is viewed as a foreign language. For students who study all their subjects in Bahasa Melayu (the mother tongue/hence the first language as well) at school and speak their mother tongue at home, they treat English as a foreign language rather than the second language.

The English syllabus is planned in line with the government's aspiration which emphasizes on the intellectual, emotional, spiritual and physical development of the individual as well as the acquisition of the language skills of listening, speaking, reading and writing including grammar and vocabulary Kementerian Pendidikan Malaysia (2000).

'At the end of the secondary school English Language program, the students should be able to read and understand prose and poetry for information and enjoyment' Kementerian Pendidikan Malaysia (2000).

As a result, the Class Reader Program (CRP) which was integrated into the teaching and learning of English was introduced. Unfortunately it was not successful due to some factors. One major factor is the teachers' as well as students' attitude towards the program. Since there was no evaluation in public examination, the program was not taken seriously.

In the year 2000, a major step was taken by the Ministry of Education to incorporate the literature component into the syllabus and was tested in public examinations for the first time. Moves towards re-establishing English Asmah Hj Omar (1992), Asmah Hj. Omar (1967), have culminated in policies to allow the use of English for the teaching of scientific and technological subjects Ramayah J. and V. Menon (1994).

The incorporation of literature in the English Language syllabus was finalized and implemented in the year 2000 beginning with Form One and Four.

The teaching and learning of literature has perhaps been given more focus and attention to improve the students' proficiency as now it is made compulsory and formally tested in the public examinations. However, the pressure of examination looming over students and teachers, the teaching and learning literature turned out to be exam-oriented and resulted in a wash back effect.

Purpose of Study: This study is conducted to explore the impact of literature components in stimulating students' interest in learning English. It is to investigate and assess the students' perceptions and attitudes towards literature and whether its incorporation in the secondary school syllabus helped to improve the students' grasp of the language. The study was conducted on form five students since these students have experienced the literature components from Form one to Form Five.

The study also investigated the students' interest to read, write and speak in the language as a result of learning Literature and whether the texts selected are suitable for them. In addition to that the study also looked at teachers' involvement and contribution to the teaching and of learning of literature in the classrooms.

\subsection{Literature Review}

Literature: 'Literature' is a body of written or oral work to stimulate the imagination and confront the reader with unique vision of life. It is a creative, universal form of expression that addresses the emotional, spiritual, or intellectual concern of humanity. Literature can be experienced privately and it is often thought of as a written form of expression, but there are many strong oral traditions in both aboriginal and modern societies Rabi'ah Yunus (2004).

In reference to the Guideline of Children's Contemporary Literature by the Ministry of Education (2004a), teaching of literature is defined as teaching the material created for and widely read, viewed and heard by children and that particular material has imaginative element.

Extensive Reading: The teaching of literature and language is inseparable. The close relationship between the language developments through literary studies can be seen in many reading programs. A study Brown (2000b), states that extensive reading is associated with reading large amounts of material. The aim is to get an overall understanding of the material. The readers are more concerned with the meaning of the text than the meaning of individual words or sentences. The characteristics of extensive reading are pupils read as much as possible, 
pupils read a variety of materials on a wide range of topics, pupils select what they want to read, pupils find out that reading has its own rewards, reading materials are well within the linguistic competence of the pupils, reading is individual and silent, reading speed is usually faster rather than slower, teachers orient pupils to the goals of the program, explain the methodology, keep track of what each pupils reads, and guide pupils and the teacher is a role model of a reader for pupils Day and Bramford (1998).

This program is an intensive reading program based on three prescribed texts per year. The texts consist of short stories and poems. Literary texts offer 'shifting horizons of meaning' Langer (1992), and they reflect the rich and fascinating diversities of our world Carter and Long (Eds.). (1996), Lazar (1993).

As stated in Ministry of Education (2004a), the benefits of having this Children's Literature program can be in the three forms that are personal and emotional gains, learning gains and language gains.

Most important of all, literature texts also facilitate the acquisition of grammar and vocabulary. Literature texts helps learners internalize the grammar and infer the meanings of words from the context Krashen (1993). In second language classrooms, poems can be used for a wide range of vocabulary exercises to develop sensitivity to the webs of association which link words to each other because poems use language which is associative, connotative and concentrated Chitravelu, S. Sithamparam and S.C. The (2001). This may help to improve a learners' feel for the language as they will be able to sense that words have a certain weight and quality Maley and Moulding (1985).

In England, literature is not only seen as sublimation of human thought, passion, feelings concerning issues which are of universal interest but also introduces the students to great minds and new forms of experience and also as means of contact with these great minds Paffard (1978).

Besides, Savvidou (2004), suggests that teaching literature is an integrated approach. Therefore, teachers need to select an approach which best serves the needs of the learners and the syllabus. Another study Rosli Talif and Jayakumaran (1994), further suggests the use of three models in the teaching of literature. They are the cultural model, the language model and the personal growth model.

The Cultural Model: The Cultural Model represents the traditional approach to teaching literature. It requires learners to explore and interpret the social, political, literary and historical context of a specific text but it also encourages learners to understand different cultures and ideologies in relation to their own.

The Language Model: It is the most common approach applied in classrooms. It enables learners to access a text in a systematic and methodical way in order to exemplify specific linguistic features. This approach offers the range of strategies used in language teaching through activities in which all activities used are to manipulate literary texts in order to serve specific linguistic goals.

The Personal Growth Model: This model attempts to link the cultural model and the language model by focusing on the particular use of language in a text, as well as placing it in a specific cultural context. Learners are encouraged to express their opinions, feelings and opinions and make connections between their own personal and cultural experiences and those expressed in the text.

\subsection{Methodology}

The research design takes into account the objectives of the study and the research questions. This is a qualitative study conducted through a survey method involving a questionnaire to elicit responses from students regarding the use of literature in language classroom. The focus is on their perception and attitudes towards literature in improving their language proficiency, the styles of teachers in the teaching of literature and also the literary texts used.

Sampling: 50 Malay students, chosen from SMK Bukit Besi, Dungun Terengganu comprising of 2 classes of Social Science make up the sample. All of them have been exposed to English Literature since Form One. The students are provided with the literary texts prescribed by the Ministry of Education consisting of both poems and short stories on local and foreign issues. They are provided with a standard package and teachers have no say on the choice of the texts. Students were assessed twice for the literature components learnt, i.e. at the PMR and SPM level.

The questionnaire consisted of three sections. The first section is the demographic variables of the respondents, the second section consisted of questions to find out the views of the respondents against a Likert-Scale and the last section is to elicit students' interest of the texts used in the classroom. The questionnaire was presented in English with full translation to make sure that the students understood all the questions and statements in it as some of the students had low English Language proficiency. 
Descriptive statistics such as mean, median and mode were used to answer the research questions guiding this study.

Data Collection and Analysis: The study is meant at getting responses from the students regarding the learning of literature and whether the learning of literature improves the students' language proficiency.

After collecting the data from the questionnaires, the researcher analyzed the data for the purpose of answering the research questions. The questionnaires were analyzed using the frequency count technique and percentages. They were presented in the form of tables and figures. Demographic variables of the respondents were also collected at the beginning of the questionnaire to obtain background information as supporting data to understand the overall analysis. The data analysis used was the SPSS statistical package readily available in software programs for convenience.

\section{Results and Discussion}

Pilot Test: Based on [18], the reliability of measure was established by testing for both consistency and stability. Consistency indicates how well an item measuring a concept is related together as a set. Cronbach's Alpha is computed in term of average inter-correlation among the items measuring the concept. The closer the Cronbach's Alpha is to 1 , the higher the internal consistency reliability. In general, reliability less than 0.6 is poor while any reliability above 0.7 is acceptable and good.

Table 1.

\begin{tabular}{|c|c|c|c|}
\hline Section & Items & Items & Cronbach Alpha $(n=30)$ \\
\hline $\mathrm{B}$ & $\begin{array}{l}\text { Does Learning English Improve Students' English Language } \\
\text { Proficiency? }\end{array}$ & 10 & 0.85 \\
\hline $\mathrm{C}$ & $\begin{array}{l}\text { Do Teachers' Styles Affect the Enjoyment and Passion of } \\
\text { Learning English Language? }\end{array}$ & 10 & 0.47 \\
\hline $\mathrm{D}$ & $\begin{array}{l}\text { Do English Literature Activities provide an Interesting and } \\
\text { enjoyable lesson? }\end{array}$ & 10 & 0.85 \\
\hline $\mathrm{E}$ & $\begin{array}{l}\text { Does Learning English Literature Improve the Students } \\
\text { Creativity in writing? }\end{array}$ & 10 & 0.89 \\
\hline $\mathrm{F}$ & $\begin{array}{l}\text { Does students' Interest in Learning English Literature depend } \\
\text { on the Text Chosen? }\end{array}$ & 10 & 0.47 \\
\hline \multirow[t]{2}{*}{ G } & Literary texts preferences by the Students. & 20 & 0.49 \\
\hline & $\begin{array}{l}\text { Overall English Proficiency of the New Graduates }(B+C+ \\
D+E+F+G)\end{array}$ & 70 & 0.88 \\
\hline
\end{tabular}

The result shown in Table 1 indicates the entire instrument as having a very strong reliability of 0.88 . In addition, reliability tests were also carried out on individual sections of the questionnaire, namely, section C, D, E, F and G. Section A, B and D showed strong reliability as indicated in the same table. However, section C, F and G indicated poor reliability. Therefore, the questionnaire was adopted for the study.

\section{Descriptive Statistics:}

The data on the parents/guardians' occupations is also taken into account to assist the researchers understand the students performance. Only 4 out of 50 students are government officers. Most of the parents/guardians do odd jobs which accounts for about $50 \%$.

Table 2 also shows the data of the English UPSR (Primary school public examination) grades achieved by the students under this study. It is found that $32 \%$ obtained a grade B, $44 \%$ grade C, $18 \%$ grade D and $6 \%$ failed in their UPSR English paper. None of them excelled, indicating average and poor proficiency entry as far as language is concerned. Information was also collected on the students' achievement for the English Language paper in PMR examination (Lower secondary public examination).

Based on the data, the percentage of students who obtained grade B, C, D and E for English Language is almost similar to the UPSR examination. This shows that the level of English among students of SMK Bukit Besi did not show much improvement, proving the fact that an extra three years to hone their proficiency in the language did not have any effect on them. 
Table 2 .

\begin{tabular}{|c|c|c|c|}
\hline Respondent's Profile & & Freq. & $\%$ \\
\hline \multirow[t]{2}{*}{ Age (years) } & 17 & 50 & 100.0 \\
\hline & Total & 50 & 100.0 \\
\hline \multirow[t]{3}{*}{ Gender } & Male & 27 & 54 \\
\hline & Female & 23 & 46 \\
\hline & Total & 50 & 100.0 \\
\hline \multirow[t]{2}{*}{ Race } & Malay & 50 & 100.0 \\
\hline & Total & 50 & 100.0 \\
\hline \multirow[t]{6}{*}{ Parents' /Guardians' Occupation } & Government Officer & 4 & 8.0 \\
\hline & Private Officer & 9 & 18.0 \\
\hline & Government non officer & 4 & 8.0 \\
\hline & Private non Officer & 8 & 16.0 \\
\hline & Others & 25 & 50.0 \\
\hline & Total & 50 & 100.0 \\
\hline \multirow[t]{5}{*}{ UPSR English Grade } & Grade B & 16 & 32.0 \\
\hline & Grade C & 22 & 44.0 \\
\hline & Grade D & 9 & 18.0 \\
\hline & Grade E & 3 & 6.0 \\
\hline & Total & 50 & 100.0 \\
\hline \multirow[t]{5}{*}{ PMR English Grade } & Grade B & 10 & 20.0 \\
\hline & Grade C & 20 & 40.0 \\
\hline & Grade D & 18 & 36.0 \\
\hline & Grade E & 2 & 4.0 \\
\hline & Total & 50 & 100.0 \\
\hline
\end{tabular}

Note*: Achievement of English

A - Distinction, B - Moderate, C - Average, D - Pass, E - Fail

Students' perception towards Literature: The following tables present data collected on the views of the respondents towards learning literature. Findings have been presented according to the research questions being answered and the hypothesis that need to be accepted or rejected to ensure that all aspects are covered in line with this study.

Research Question 1: Does learning English Literature improve the students' English Language proficiency?

Table 3. Improvement in proficiency level

\begin{tabular}{cccccc}
\hline Mean & Max. mean & Min. mean & Mid-pt. value & Mode & Std. Dev. \\
\hline 33.07 & 50 & 10 & 30.0 & 27 & 5.77 \\
\hline
\end{tabular}

In terms of perception of the students the mean score is 33.07. Therefore, it is clear that students have improved on their English Language proficiency through learning English Literature since the mean score obtained, 33.07, is higher than the mid- point value 30. In this study, English Language proficiency is deemed to have improved if the score obtained from the students' sample exceeds the mid-point value. Then, hypothesis 1 is rejected.

Research Question 2: Do teachers' styles affect the enjoyment and passion of learning English literature?

Table 4. Teacher's style affecting learning through literature

\begin{tabular}{cccccc}
\hline Mean & Max. mean & Min. mean & Mid-pt. value & Mode & Std. Dev. \\
\hline 40.30 & 50 & 10 & 30.0 & 42.0 & 2.78 \\
\hline
\end{tabular}


Table 4 shows the mean score of 40.30 for 10 items in this section. The table contains the summary of all the respondents' choices in section C of the questionnaire. The mid-point value is 30 . Since the mean of 40.30 well exceeds the mid-point value, it can be said that respondents in the sample were in favor of the statement that teachers' styles do affect the enjoyment and passion of learning English Literature. Therefore, hypothesis 2 is rejected.

Research Question 3: Do English Literature activities provide interesting and enjoyable lesson?

Table 5. Responses on the English literature activities on the lesson

\begin{tabular}{cccccc}
\hline Mean & Max. mean & Min. mean & Mid-pt. value & Mode & Std. Dev. \\
\hline 37.47 & 50 & 10 & 30.0 & 37.0 & 5.73
\end{tabular}

Table 5 shows that the mean value obtained from the 50 respondents on whether English Literature provides interesting and enjoyable lesson is 37.47 . As this is far higher than the mid-point value of 30 , it can be concluded that the sample perceived group is in favor of the English Literature activities. In light of the findings above, hypothesis 3 is rejected.

Research Question 4: Does learning English Literature improve students' creativity in writing?

Table 6 shows the mean scores as obtained from the 50 respondents as to whether teaching/ learning English Literature improves Students' creativity in writing. As the mean value is 35.40 and it is also higher than the mid-point of 30, it can be summarized that the selected respondents agreed that the learning of English Literature can improve the students' creativity in writing.

Based on the analysis, hypothesis 4 is also rejected.

Table 6. English literature improve students' creativity in writing

\begin{tabular}{cccccc}
\hline Mean & Max. mean & Min. mean & Mid-pt. value & Mode & Std. Dev. \\
\hline 35.40 & 50 & 10 & 30.0 & 30.0 & 5.89
\end{tabular}

Research Question 5: Do students' interest in learning English Literature depend on the text chosen?

Table 7 shows the result of the finding out whether the texts chosen determine the interest of students learning literature. As can be seen from the table above, the mean value is 38.20 which is higher than the mid-point, 30 . The result indicates that the students' interest is dependent on the texts selected. In view of the findings H5 had to be rejected.

Table 7. Selected texts determine the students' interest

\begin{tabular}{cccccc}
\hline Mean & Max. mean & Min. mean & Mid-pt. value & Mode & Std. Dev. \\
\hline 38.20 & 50 & 10 & 30.0 & 37.0 & 4.17
\end{tabular}

\section{Conclusion}

The roles of literature in the language curriculum are inseparable. Most teachers realize the importance of the teaching of the literature subject to the students because the subject has broadened the students' view point about cultures and world views beside improve their grasp of the target language. Based on the study, it was found out that teachers' styles as well as the text chosen also play important roles in the interests of the students.

With regard to the literary texts selected, it was found that the students had their own choice of texts. Simple language with simple issues in the texts and familiarity with the texts were their first choice. Learning literature actually encourages students to read and in doing so they will unconsciously improve their vocabulary. The vast vocabulary helps them to write confidently and creatively.

Furthermore, general knowledge and the development of the intellect are involved in the learning of literature. However, many factors contribute towards the successful implementation of the literature programme in schools.

This study is limited to the feedback given by fifty students as to whether learning literature enhances the students' proficiency of the English Language. Therefore, further research could be carried out to investigate students' feedback in the urban area in comparison to rural areas, and more respondents should be involved.

An experimental study is suggested to be carried out to figure out the effectiveness of the method currently used pertaining to the teaching of literature in the classroom. Research could also be conducted on the effectiveness of the training and courses organized by the education department or the curriculum centre in the effort to inculcate interest of the students to learn literature as part of English Language learning subject and how the interest 
affects their passion for the subject.

\section{References}

Asmah Hj Omar. (1992). The Linguistic Scenery in Malaysia [Dewan Bahasa dan Pustaka]. Ministry of Education, Kuala Lumpur, Malaysia.

Asmah Hj. Omar. (1967). The Malaysian Mosaic of Language dalam Essays on Malaysian Linguistics. Kuala Lumpur: Dewan Bahasa dan Pustaka.

Brown, R. (2000b). Extensive Reading in the EFL Class (Extensive Reading in Practice Colloqium). Retrieved February 19, 2009, from http://www.extensivereading.net/er/brown.html

Carter, R., \& Long, M. N. (Eds.). (1996). Language, Literature and the Learner: Creative classroom practice. New York: Pearson Education Inc.

Chitravelu, N., Sithamparam, S., \& The, S. C. (2001). ELT Methodology. Principles and Practice. Selangor: Penerbit Fajar Bakti Sdn. Bhd.

Day, R., \& Bramford, J. (1998). Extensive Reading in the Second Language Classroom. Retrieved August 13, 2008, from http://www.extensivereading.net/er/plaister.html

Kementerian Pendidikan Malaysia. (2000). Sukatan Pelajaran Kurikulum Bersepadu Sekolah Menengah [Bahasa Inggeris]. Selangor: Pusat Perkembangan Kurikulum.

Krashen, S. (1993). The Power of Reading. Eaglewood: Libraries Unlimited.

Langer, J. (1992). Rethinking Literature Instruction. In J. Langer (Ed.), Literature Instruction: A focus on Students' Response (pp. 35-53). Urbana, IL: National Council of Teachers of English.

Lazar, G. (1993). Literature and Language Teaching. Cambridge: CUP. http://dx.doi.org/10.1017/CBO9780511733048

Maley, A., \& Moulding, S. (1985). Poem into Poem. Cambridge: Cambridge University Press.

Ministry of Education. (2004a). Guidelines to Extensive Reading Programme for Contemporary Children's Literature of Standard 4. Kuala Lumpur: Pusat Perkembangan Kurikulum.

Paffard, M. (1978). Thinking about English. England: A Member of the Pentos Group.

Rabi'ah Yunus. (2004). A Study of Using Internet to Promote Self-Directed Learning (SDL) in Learning Literature Among Adult Learners. Shah Alam: UiTM.

Ramayah, J., \& Menon, V. (1994, January 9). Bahasa Policy Stays. The New Sunday Times.

Rosli Talif, \& Jayakumaran, M. (1994, October). Using Literature in an Advanced Situation: Issue and Prospects. The English Teacher, XXIII. Retrieved March 13, 2008, from http://www.melta.org.my/ET/1994/main8.html

Savvidou, C. (2004). An Integrated Approach to Teaching Literature in the EFL Classroom. Retrieved August 30, 2009, from http://iteslj.org/Techniques/Savvidou-Literature.html

Sekaran, U. (2003). Business Research Methods for Managers: A Skill-Building Approach (4th ed.). NY: John Wiley \& Sons, Inc. 